\title{
Does knee pain in the community behave like a regional pain syndrome? Prospective cohort study of incidence and persistence
}

\author{
K T Palmer, I Reading, M Calnan, C Linaker, D Coggon
}

Ann Rheum Dis 2007;66:1190-1194. doi: 10.1136/ard.2006.061481

See end of article for authors' affiliations

Correspondence to Dr Keith Palmer, MRC Epidemiology Resource Centre, Southampton General Hospital, Tremona Road, Southampton, SO16 6YD, UK; ktp@mrc.soton.ac. uk

Accepted 30 October 2006 Published Online First 17 November 2006 pain in the community behaves like a regional pain syndrome, Objectives: To investigate whether knee pain in the community behaves like a regional pain synd
determined by its association with mental health, self-rated health (SRH) and beliefs about prognosis. Methods: An 18-month postal follow-up was conducted in 1798 working-aged subjects, sampled from the community. At baseline questions were asked about pain in the knee lasting $\geqslant 1$ day in the previous 12 months, mental health (Short-Form 36), somatising tendency (elements of the Brief Symptom Inventory), SRH and concern about 12-month prognosis. At follow-up we asked about knee pain during the last 4 weeks, and whether it had been present for $\geqslant 14$ days or prescription-treated. Associations with incidence and persistence were explored using logistic regression.

Results: The 1256 participants (70\% response) comprised 468 with knee pain at baseline and 788 without. Among the former, $49 \%$ had persistent knee pain at follow-up, while among the latter, $15 \%$ reported new symptoms. Incident prescription-treated knee pain was strongly associated with all of the mental health variables and with SRH. The odds of knee pain persisting were significantly raised in the least versus most favourable bands of somatising tendency and SRH, and persistence was also significantly more common among those who at baseline were concerned that they would still have a problem in 12 months.

Conclusions: Our observations support the hypothesis that knee pain in the community shares risk factors in common with other non-specific regional pain syndromes.
$\mathrm{K}$ nee pain is a common symptom in the general population. ${ }^{1}$ In the UK, a community survey in Staffordshire found that $47 \%$ of people aged $>50$ years had experienced knee pain over a 12-month period, including 25\% whose symptoms had lasted $>3$ months; ${ }^{2}$ a second survey, in Nottingham, estimated the overall 12-month prevalence in 40-79 year olds at $29 \%$, with rates tending to increase with age; $^{3}$ and a third, in Oxfordshire, estimated a 1-year prevalence of $33 \%$ in $>65$ year olds, among whom $58 \%$ were still in pain a year later. ${ }^{4}$ In another survey from Staffordshire, $10 \%$ of knee pain sufferers had consulted their family doctor for over a year, ${ }^{5}$ and in a study from Dutch primary care, most consulters remained symptomatic when followed up over 12 months. ${ }^{6}$

Knee pain can be caused by a variety of pathologies, including osteoarthritis (OA), tears of the meniscal cartilage, and tears and strains of the knee ligaments. Most knee pain in the community does not arise from OA and does not necessarily share the same risk factors. ${ }^{7-9}$ In the NHANES-I study, only $15 \%$ of subjects with knee pain had radiologically established knee OA, while more than half of those with radiological OA were not in pain. ${ }^{10}$ Furthermore, correlates of radiological disease (eg, sex, race, obesity) were generally not associated with knee pain, which showed a much stronger relation with poor psychological well-being. ${ }^{11}$ Similarly, in several surveys of knee pain patients, mental ill-health was more evident in the absence of $\mathrm{OA}$, and physical mechanical factors less so. ${ }^{12-14}$ Hadler observed that: "the epidemiology of [knee] OA and the epidemiology of knee pain have little in common". ${ }^{7}$

Some authors have described knee pain in the community as a form of regional pain syndrome, similar to low-back pain (LBP), non-specific upper limb pain, or fibromyalgia. ${ }^{15}{ }^{16}$ If so, then in addition to mental ill-health, ${ }^{317}$ it might share other risk factors in common with these complaints, such as health anxiety, poor self-rated health (SRH) and negative illness beliefs. The evidence base on this is much more limited than for pain at other anatomical sites, and is largely cross-sectional in nature. It thus fails to distinguish cause from effect, and risk factors for incidence from those for persistence. Moreover, some potential risk factors such as general tendency to express distress from somatic symptoms (somatising tendency) do not seem to have been explored at all; and others that have proved important for the management of LBP have received only scant attention. ${ }^{6}$

As part of a population-based prospective study, ${ }^{18}{ }^{19}$ we therefore investigated whether somatising tendency, low mood, and poor SRH predict incidence and persistence of knee pain, and whether concern about prognosis predicts persistence.

\section{METHODS}

The study sample was drawn from an earlier cross-sectional survey. ${ }^{18}$ At baseline, a questionnaire had been mailed to a stratified random sample of 4998 subjects aged 25-64 years, chosen from the age-sex registers of five general practices in the west of England. Among a total of 2632 respondents, 1798 agreed to be followed up and were mailed a second time at an interval of 18 months, with a single reminder, if required, after a further 3 weeks. Ethical approval was provided by the NHS Southwest Local Research Ethics Committee.

\section{Baseline}

At baseline, we asked about pain in the knee lasting $\geqslant 1$ day during the past 12 months. Those who reported such pain provided supplementary details on the number of days or months of pain during this period, and about whether, at its worst, the pain made it difficult or impossible to sleep, dress or

Abbreviations: $\mathrm{Cl}$, confidence interval; LBP, low back pain; $\mathrm{OA}$, osteoarthritis; $\mathrm{OR}$, odds ratio; $\mathrm{SRH}$, self-rated health 


\begin{tabular}{|c|c|c|}
\hline Characteristic at baseline & $\begin{array}{l}\text { No. at baseline } \\
(n=1798)(\%)\end{array}$ & $\begin{array}{l}\text { No. }(\%) \text { at follow-up } \\
(n=1256)(\%)\end{array}$ \\
\hline \multicolumn{3}{|l|}{ Sex: } \\
\hline Male & $816(45)$ & $562(45)$ \\
\hline Female & 979 (54) & 694 (55) \\
\hline Unknown & $3(0.2)$ & \\
\hline \multicolumn{3}{|l|}{ Age group (years): } \\
\hline$<35$ & $236(13)$ & $131(10)$ \\
\hline 35-39 & $189(11)$ & $114(9)$ \\
\hline $40-44$ & $241(13)$ & 165 (13) \\
\hline $45-49$ & $268(15)$ & $188(15)$ \\
\hline $50-54$ & 266 (15) & $200(16)$ \\
\hline $55-59$ & $354(20)$ & $274(22)$ \\
\hline$\geqslant 60$ & $244(14)$ & $184(15)$ \\
\hline \multirow{2}{*}{\multicolumn{3}{|c|}{$\begin{array}{l}\text { Knee pain during past } \\
12 \text { months: }\end{array}$}} \\
\hline & & \\
\hline Any & $643(36)$ & $468(37)$ \\
\hline$>6$ months & 149 (8) & $107(9)$ \\
\hline Disabling & $88(5)$ & $61(5)$ \\
\hline Self-rated health: & & \\
\hline Fair/poor & $247(14)$ & $148(12)$ \\
\hline \multicolumn{3}{|l|}{ Somatisation score: } \\
\hline Worst band & $685(38)$ & 461 (37) \\
\hline SF-36 MH score: & & \\
\hline Worst band & $617(34)$ & $406(32)$ \\
\hline \multicolumn{3}{|c|}{ Combined mental health score: } \\
\hline Worst band & 345 (19) & $216(17)$ \\
\hline
\end{tabular}

do household tasks. Subsequently those with knee pain at baseline were subcategorised according to whether symptoms were "frequent" (present for $\geqslant 6$ months in aggregate over the past year) or "disabling" (interfering with all three of sleeping, dressing and performing household tasks). Similar information was collected for LBP.

The initial questionnaire also included items on mental health, SRH and (in those with symptoms) concern about prognosis. Specifically, we assessed low mood using the mental health subscale of the Short-Form 36 (SF-36 MH), ${ }^{20}$ tendency to somatise using elements of the Brief Symptom Inventory, ${ }^{21}$ and SRH using the question "In general would you say your health is ... excellent/very good/good/fair/poor?".22 For low mood and somatising tendency, subjects were categorised into three bands representing thirds of the distribution of scores for all subjects. In addition, as described more fully elsewhere, ${ }^{19}$ we created a composite mental health variable (composite mental health score) in three bands, based on the joint distribution of SF-36 MH and somatising tendency bands (worst = top third of both scales; best = bottom third of both scales; intermediate $=$ other combinations). These questionnaire items have been assessed previously in various setting $\mathrm{s}^{23-25}$ and found by us to have predictive validity for regional pain at other sites. ${ }^{19}$

Finally, at baseline, we asked about occupation and whether a typical working day involved lifting weights $\geqslant 25 \mathrm{~kg}$ by hand, kneeling or squatting for $>1 \mathrm{~h}$, climbing a ladder, or digging and shovelling.

\section{Follow-up}

The second questionnaire asked about knee pain lasting $\geqslant 1$ day during the last 4 weeks of follow-up, including: (a) "any" knee pain; (b) "frequent" knee pain (ie, present for $\geqslant 14$ days during the past 4 weeks); and (c) "prescription-treated" knee pain (knee pain for which prescription treatment had been taken during the past 4 weeks). All three outcomes were considered in analyses of persistence and incidence.

Subjects who were free of knee pain at baseline contributed to the analysis of risk factors for incidence, while those who

had symptoms at baseline were included in the analysis of persistence. Associations with baseline characteristics were assessed by logistic regression with adjustment for potential confounders, and findings were expressed as odds ratios (ORs), with associated 95\% confidence intervals (CIs). All models were adjusted a priori for the general practice from which the subject was recruited and for age (in seven bands) and sex, both of which are potential risk factors for incidence and persistence. ${ }^{2} 6172627$ Additionally, in analyses of persistence, we explored the impact of adjusting also for frequency of knee pain and disability for everyday tasks at baseline. However, as these features could lie on the causal pathway between mental health/beliefs and persistence of symptoms we present our findings both with and without this adjustment.

Finally, we performed two sensitivity analyses to test the robustness of our findings. As some knee pain could have been referred from the lower back, we repeated the main analyses for the subset of respondents with no LBP in the past 12 months at baseline. In addition, among those in work, we explored the effect of adjusting for social class (manual versus non-manual) and occupational physical activities at baseline (lifting weights, kneeling/squatting, climbing and digging/shovelling, defined as above).

All analyses were conducted using STATA version 9.2.

\section{RESULTS}

Table 1 provides details of the response. ${ }^{19}$ Usable responses were returned by 1256 (70\%) of the subjects who were sent a followup questionnaire. Respondents, although somewhat older than those mailed (mean age 49 vs. 48 years), differed little by sex, frequency and severity of pain at baseline, SRH or indices of mental health. The final sample comprised 468 subjects with knee pain in the 12 months before baseline and 788 who were free of this symptom.

Persistence was common in the former group: 49\% (95\% CI $44 \%-53 \%$ ) reported knee pain at follow-up, including $22 \%$ with frequent and $21 \%$ with prescription-treated knee pain (table 2 ). Incident symptoms were less common-15\% for any knee pain and $<5 \%$ for frequent and prescription-treated knee pain.

Table 3 shows the relation of incident knee pain to SRH and mental health at baseline. The odds of "any" knee pain and "frequent" knee pain were raised 1.4-1.8-fold in those in the worst band compared with the best band of each variable. Individual risk estimates were generally not significant at the $5 \%$ level, although in each case an exposure-response gradient was suggested. Associations with incident prescription-treated pain were stronger, although based on smaller numbers and with wider confidence intervals, and p values for trend were all statistically significant at the $1 \%$ level. Thus, for SF-36 MH (worst versus best band) the OR was 4.2 (95\% CI 1.6 to 11.3 ), and it was similarly elevated for somatising tendency (OR 3.1,

Table 2 Prevalence of knee pain in the last 4 weeks of follow-up according to pain status at baseline

\begin{tabular}{|c|c|c|c|c|c|}
\hline \multirow{3}{*}{$\begin{array}{l}\text { Knee } \\
\text { pain at } \\
\text { baseline* }\end{array}$} & \multicolumn{5}{|c|}{ Knee pain in last 4 weeks of follow-up } \\
\hline & Any & \multicolumn{2}{|c|}{ Frequent } & \multicolumn{2}{|c|}{ Prescription treated } \\
\hline & $n \% \quad(95 \% \mathrm{Cl})$ & $n \%$ & $(95 \% \mathrm{Cl})$ & $n \%$ & $(95 \% \mathrm{Cl})$ \\
\hline $\begin{array}{l}\text { Knee pain } \\
\text { absent } \\
(n=788)\end{array}$ & $\begin{array}{l}119 \text { (12.7 to } 17.8 \\
15.1\end{array}$ & $\begin{array}{l}30 \\
3.8\end{array}$ & (2.6 to 5.4 ) & $\begin{array}{l}34 \\
4.3\end{array}$ & $(3.0$ to 6.0$)$ \\
\hline $\begin{array}{l}\text { Knee pain } \\
\text { present } \\
(n=468)\end{array}$ & $\begin{array}{l}227 \text { (43.9 to } 53.1 \\
48.5\end{array}$ & $\begin{array}{l}102 \\
21.8\end{array}$ & (18.1 to 25.8 ) & $\begin{array}{l}96 \\
20.5\end{array}$ & (16.9 to 24.5$)$ \\
\hline
\end{tabular}

*Pain in the knee in the previous 12 months. 


\begin{tabular}{|c|c|c|c|c|c|}
\hline \multirow[b]{3}{*}{$\begin{array}{l}\text { Characteristic at } \\
\text { baseline }\end{array}$} & \multirow[b]{3}{*}{$\begin{array}{l}\text { No. in } \\
\text { sample* }\end{array}$} & \multicolumn{4}{|c|}{ Knee pain in last 4 weeks at follow-up } \\
\hline & & \multicolumn{2}{|c|}{ Any knee pain } & \multicolumn{2}{|c|}{$\begin{array}{l}\text { Prescription-treated } \\
\text { knee pain }\end{array}$} \\
\hline & & $\begin{array}{l}\text { No. } \\
\text { with } \\
\text { pain }\end{array}$ & OR $(95 \% \mathrm{Cl})$ & $\begin{array}{l}\text { No. } \\
\text { with } \\
\text { pain }\end{array}$ & OR $(95 \% \mathrm{Cl})$ \\
\hline \multicolumn{6}{|l|}{ SRH } \\
\hline Excellent & 125 & 17 & 1.0 & None & \\
\hline $\begin{array}{l}\text { Good/very } \\
\text { good }\end{array}$ & 586 & 86 & $\begin{array}{l}1.1(0.6 \text { to } \\
1.9)\end{array}$ & 24 & $1.0 \dagger$ \\
\hline Fair/poor & 75 & 16 & $\begin{array}{l}1.6(0.7 \text { to } \\
3.4)\end{array}$ & 10 & $\begin{array}{l}2.7 \text { (1.2 to } \\
6.2 \text { ) }\end{array}$ \\
\hline \multicolumn{6}{|l|}{$\begin{array}{l}\text { Somatising } \\
\text { tendency score }\end{array}$} \\
\hline Best & 285 & 35 & 1.0 & 7 & 1.0 \\
\hline Intermediate & 240 & 34 & $\begin{array}{l}1.1 \text { (0.7 to } \\
1.8)\end{array}$ & 6 & $\begin{array}{l}1.0(0.3 \text { to } \\
3.2)\end{array}$ \\
\hline Worst & 239 & 46 & $\begin{array}{l}1.6 \text { (1.0 to } \\
2.7)\end{array}$ & 18 & $\begin{array}{l}3.1 \text { ( } 1.2 \text { to } \\
8.0)\end{array}$ \\
\hline \multicolumn{6}{|l|}{ SF-36 MH score } \\
\hline Best & 323 & 42 & 1.0 & 6 & 1.0 \\
\hline Intermediate & 213 & 34 & $\begin{array}{l}1.3(0.8 \text { to } \\
2.2)\end{array}$ & 8 & $\begin{array}{l}1.9 \text { (0.6 to } \\
5.7)\end{array}$ \\
\hline Worst & 244 & 40 & $\begin{array}{l}1.4(0.9 \text { to } \\
2.3)\end{array}$ & 18 & $\begin{array}{l}4.2(1.6 \text { to } \\
11.3)\end{array}$ \\
\hline \multicolumn{6}{|c|}{$\begin{array}{l}\text { Combined mental } \\
\text { health score }\end{array}$} \\
\hline Best & 172 & 21 & 1.0 & 3 & 1.0 \\
\hline Intermediate & 477 & 70 & $\begin{array}{l}1.2(0.7 \text { to } \\
2.1)\end{array}$ & 16 & $\begin{array}{l}1.8(0.5 \text { to } \\
6.5)\end{array}$ \\
\hline Worst & 117 & 24 & $\begin{array}{l}1.8(0.9 \text { to } \\
3.4)\end{array}$ & 12 & $\begin{array}{l}5.2(1.4 \text { to } \\
20.1)\end{array}$ \\
\hline
\end{tabular}

Separate models were constructed for each row variable. All risk estimates were adjusted for age (in seven bands), sex and practice. SRH, Self-rated health.

${ }^{*}$ A few respondents failed to answer all the questions.

†As no subjects with prescription-treated knee pain reported "excellent"

$\mathrm{SRH}$, the baseline for comparison was redefined as "good/very good" $\mathrm{SRH}$.

95\% CI 1.2 to 8.0 ) and for combined mental health score (OR $5.2,95 \%$ CI 1.4 to 20.1 ).

Table 4 summarises the equivalent findings for persistence of knee pain. Only a weak association was found with SF-36 MH, but associations with the other variables were stronger, and all worst versus best band comparisons were significant at the 5\% level with positive exposure-response relationships. ORs ranged from 2.4 to 14.4, being especially strong for SRH (frequent and prescription-treated knee pain) and combined mental health score ("any" and prescription-treated knee pain). Adjustment for frequency of knee pain and the presence of associated disability at baseline (Model 2) only weakened associations slightly.

Table 5 shows relations between persistence of knee pain and concern about prognosis. After adjustment for age, sex and practice, the odds of persistent pain were increased about threefold in subjects who were concerned that their knee pain would still be a problem in 12 months time (Model 1). ORs were little changed after additional adjustment for frequency of knee pain and report of disability at baseline (Model 2), and for Model 2 factors plus combined mental health score (Model 3 ).

Finally, in two sets of sensitivity analyses we explored the effects of excluding subjects with LBP at baseline and of adjusting for occupational physical activities. The former analyses were based on 354 subjects without and 156 with knee pain at baseline. Associations with SRH and indices of mental health were, if anything, strengthened in this analysis. Thus, for example, the OR for somatising tendency (worst versus best band) was 2.7 (95\% CI 1.2 to 6.0) for incidence of "any" knee pain and 5.3 (95\% CI 1.8 to 15.4) for persistence of "any" knee pain, as compared with ORs of 1.6 and 3.6, respectively, for the whole sample. Our occupational analysis was based on 613 workers without knee pain and 328 workers with knee pain at baseline. Several of the physical risk factors we inquired about showed univariate associations with knee pain incidence (especially kneeling or squatting $>1 \mathrm{~h} /$ day and being a manual worker) or knee pain persistence (especially climbing a ladder); however, associations with SRH and the mental health variables were only slightly lower when social class and all of the physical occupational risk factors were added to the main regression models and the analyses for tables 3-5 repeated (data available on request).

\section{DISCUSSION}

Our findings indicate that incidence and persistence of knee pain in working age adults from the general community are both significantly associated with low mood, tendency to somatise, and poor SRH, and that concern over prognosis is a determinant of persistence. Associations tended to be stronger for more severe outcomes, and to exhibit exposure-response relations. Somatising tendency was a stronger predictor of persistence than low mood. Although physical activities at work were moderate independent risk factors for incidence and persistence, they did not confound or explain the associations with mental health or health beliefs.

Knee pain is likely to follow a relapsing and recurring course for many individuals, and this poses challenges in the definition of incidence and persistence. For each outcome we looked for symptoms during the final 4 weeks of follow-up. For incidence, we also required subjects to be free of symptoms for the 12 months prior to baseline (rather than the past 4 weeks, as in some other studies), to distinguish new episodes from ongoing symptoms. Persistence was defined in terms of symptoms at baseline and follow-up; it should be recognised, however, that some subjects may have enjoyed symptom-free periods in between.

Our findings need to be judged in the context of several strengths and weaknesses of study design. The original sampling frame (patients registered with British general practices) is likely to have been representative of the general population in the area studied (almost everyone in Britain registers with a family doctor). The sample size was fairly large, and the follow-up rate was reasonable at $70 \%$. Furthermore, responders and drop-outs were similar in terms of the main study factors of interest. Although the final study sample represented only a minority of those canvassed at the initial cross-sectional phase, we have no reason to expect responders to be unrepresentative of the population at large in terms of longitudinal associations between mental health and knee pain. It also seems unlikely that selective response at baseline and at follow-up could bias findings so as to create artefactually the multiple exposure-response relationships observed. Also, to the extent that the survey was presented to participants as a general study of aches and pains in the community, in which knee pain was not a particular focus, they are likely to have blinded to the main hypotheses tested here.

One weakness was that respondents with knee pain were not subject to radiological investigation or detailed clinical assessment. A second was that no space could be allotted, in a broad questionnaire about multisite regional pain, to certain risk factors (body mass index and past history of knee injury) that ideally would have been controlled for in analysis. The former is a clear limitation, but we believe the impact of the latter to be slight. The relation of knee pain to physical mechanical factors seems less strong in those without OA (probably the majority of 
Table 4 Associations of persistence of knee pain with selfrated health and mental health at baseline

\begin{tabular}{|c|c|c|c|}
\hline \multirow{3}{*}{$\begin{array}{l}\text { Characteristic at } \\
\text { baseline }\end{array}$} & \multicolumn{3}{|c|}{ Knee pain in last 4 weeks at follow-up } \\
\hline & \multirow{2}{*}{$\begin{array}{l}\text { No with } \\
\text { pain/No } \\
\text { in sample }\end{array}$} & \multirow{2}{*}{$\begin{array}{l}\text { Model } 1 \\
\text { OR }(95 \% \mathrm{Cl})\end{array}$} & \multirow{2}{*}{$\begin{array}{l}\text { Model } 2 \\
\text { OR }(95 \% \text { Cl) }\end{array}$} \\
\hline & & & \\
\hline \multicolumn{4}{|l|}{ "Any" knee pain } \\
\hline \multicolumn{4}{|l|}{ Self-rated health } \\
\hline Excellent & $17 / 45$ & 1.0 & 1.0 \\
\hline Good/very good & $157 / 348$ & $1.2(0.6$ to 2.3$)$ & $1.2(0.6$ to 2.3$)$ \\
\hline Fair/poor & $52 / 73$ & $3.4(1.5$ to 7.7$)$ & $2.8(1.2$ to 6.7$)$ \\
\hline \multicolumn{4}{|c|}{ Somatising tendency score } \\
\hline Best & $25 / 90$ & 1.0 & 1.0 \\
\hline Intermediate & $61 / 140$ & $1.9(1.1$ to 3.5$)$ & 1.7 (0.9 to 3.2$)$ \\
\hline Worst & $131 / 222$ & $3.6(2.1$ to 6.3$)$ & $3.2(1.8$ to 5.7$)$ \\
\hline \multicolumn{4}{|l|}{ SF-36 MH score } \\
\hline Best & $77 / 168$ & 1.0 & 1.0 \\
\hline Intermediate & $60 / 1$ & $1.0(0.6$ to 1.6$)$ & $1.0(0.6$ to 1.6$)$ \\
\hline Worst & $86 / 162$ & $1.4(0.9$ to 2.1$)$ & $1.3(0.8$ to 2.1$)$ \\
\hline \multirow{2}{*}{\multicolumn{4}{|c|}{$\begin{array}{l}\text { Combined mental health } \\
\text { score }\end{array}$}} \\
\hline score & & & \\
\hline Best & $11 / 48$ & 1.0 & 1.0 \\
\hline Intermediate & $151 / 306$ & 3.5 (1.7 to 7.3$)$ & $2.8(1.3$ to 6.0$)$ \\
\hline Worst & $55 / 99$ & 9 to 9.7$)$ & $3.4(1.5 \mathrm{tc}$ \\
\hline \multirow{2}{*}{\multicolumn{4}{|c|}{ Frequent knee pain }} \\
\hline & & & \\
\hline Excellent & $3 / 45$ & 1.0 & 1.0 \\
\hline Good/very good & $68 / 348$ & $2.9(0.8$ to 9.7$)$ & $2.7(0.7$ to 9.7$)$ \\
\hline Fair/poor & $31 / 73$ & $7.8(2.1$ & ) 5.8 (1.4 to 23.5$)$ \\
\hline \multicolumn{4}{|c|}{ Somatising tendency score } \\
\hline Best & $10 / 90$ & 1.0 & 1.0 \\
\hline Intermediate & $3 / 140$ & $1.8(0.8$ to 3.9$)$ & $1.5(0.6$ to 3.6$)$ \\
\hline Worst & $61 / 222$ & $2.8(1.3$ to 5.8$)$ & $2.3(1.1$ to 5.3$)$ \\
\hline \multicolumn{4}{|l|}{ SF-36 MH score } \\
\hline Best & & 1.0 & 1.0 \\
\hline Intermediate & $25 / 133$ & $0.9(0.5$ to 1.6$)$ & $0.8(0.4$ to 1.5$)$ \\
\hline Worst & & & $1.1(0.6$ to 2.1$)$ \\
\hline \multicolumn{4}{|c|}{ Combined mental health } \\
\hline \multicolumn{4}{|c|}{ score } \\
\hline Best & $6 / 48$ & 1.0 & 1.0 \\
\hline Intermediate & $66 / 306$ & $1.8(0.7$ to 4.5$)$ & $1.1(0.4$ to 3.1$)$ \\
\hline Worst & $27 / 99$ & $2.4(0.9$ to 6.6$)$ & $1.5(0.5$ to 4.5$)$ \\
\hline \multirow{2}{*}{\multicolumn{4}{|c|}{$\begin{array}{l}\text { Prescription-treated knee } \\
\text { pain } \\
\text { Self-rated health }\end{array}$}} \\
\hline & & & \\
\hline Excellent & $2 / 45$ & & 1.0 \\
\hline Good/very good & $58 / 348$ & $3.5(0.8$ to 15.4$)$ & 3.5 (0.7 to 16.2$)$ \\
\hline Fair/poor & $36 / 73$ & 14.4 (3.1 to 67.1 & 1) 12.1 (2.4 to 60.9$)$ \\
\hline \multicolumn{4}{|c|}{ Somatising tendency score } \\
\hline Best & $8 / 90$ & 1.0 & 1.0 \\
\hline Intermediate & $18 / 140$ & $1.3(0.5$ to 3.2$)$ & $1.1(0.4$ to 2.9$)$ \\
\hline Worst & $65 / 222$ & 3.4 (1.5 to 7.7$)$ & $2.9(1.2$ to 6.9$)$ \\
\hline \multicolumn{4}{|l|}{ SF-36 MH score } \\
\hline Best & $26 / 168$ & 1.0 & 1.0 \\
\hline Intermediate & $29 / 133$ & $1.5(0.8$ to 2.8$)$ & $1.5(0.8$ to 3.0$)$ \\
\hline Worst & $39 / 162$ & $1.5(0.8$ to 2.7$)$ & $1.4(0.7$ to 2.6$)$ \\
\hline \multicolumn{4}{|c|}{$\begin{array}{l}\text { Combined mental health } \\
\text { score }\end{array}$} \\
\hline Best & $3 / 48$ & 1.0 & 1.0 \\
\hline Intermediate & $59 / 306$ & 3.4 (1.0 to 11.9$)$ & ) 2.7 (0.8 to 9.9 ) \\
\hline Worst & 29/99 & $5.5(1.5$ to 20.0$)$ & 4.0 (1.0 to 15.5$)$ \\
\hline
\end{tabular}

Separate models were constructed for each row variable.

In Model 1 risk estimates were adjusted for age, sex and general practice. In Model 2, risk estimates were adjusted for age, sex, general practice and characteristics of pain at baseline (frequency and associated disability).

our study sample); confounding could only explain associations with psychological risk factors if uncontrolled variables were common and important risk factors for knee pain, and were unequally distributed between exposure groups according to the dose-response gradients we found. This seems unlikely.

A more plausible explanation of the findings is that most cases of knee pain in the community behave like LBP and nonspecific upper limb pain, in sharing the characteristics and associations of regional pain syndromes. Thus persistence of LBP has been associated with poor $\mathrm{SRH}^{28}{ }^{29}$ fear-avoidance
Table 5 Associations of persistent knee pain with concern over prognosis

\begin{tabular}{|c|c|c|c|}
\hline & \multicolumn{3}{|c|}{ Knee pain in last 4 weeks of follow-up } \\
\hline & Any & Frequent & $\begin{array}{l}\text { Prescription- } \\
\text { treated }\end{array}$ \\
\hline \multicolumn{4}{|l|}{$\begin{array}{l}\text { Concerned knee pain } \\
\text { will still be a problem } \\
\text { in } 12 \text { months }(n, \%):\end{array}$} \\
\hline No & $\begin{array}{l}24 / 95 \\
(25 \%)\end{array}$ & $\begin{array}{l}6 / 95 \\
(6 \%)\end{array}$ & $\begin{array}{l}5 / 95 \\
(5 \%)\end{array}$ \\
\hline Yes & $\begin{array}{l}202 / 367 \\
(55 \%)\end{array}$ & $\begin{array}{l}96 / 367 \\
(26 \%)\end{array}$ & $\begin{array}{l}91 / 367 \\
(25 \%)\end{array}$ \\
\hline \multicolumn{4}{|l|}{ OR $(95 \% \mathrm{Cl})$} \\
\hline Model 1 & $\begin{array}{l}3.3 \\
\text { (2.0 to } 5.5)\end{array}$ & $\begin{array}{l}4.6 \\
(1.9 \text { to } 11.0)\end{array}$ & $\begin{array}{l}5.4 \\
(2.1 \text { to } 14.1)\end{array}$ \\
\hline Model 2 & $\begin{array}{l}2.7 \\
(1.6 \text { to } 4.6)\end{array}$ & $\begin{array}{l}2.6 \\
(1.1 \text { to } 6.5)\end{array}$ & $\begin{array}{l}3.8 \\
(1.4 \text { to } 10.2)\end{array}$ \\
\hline Model 3 & $\begin{array}{l}2.7 \\
(1.5 \text { to } 4.8)\end{array}$ & $\begin{array}{l}3.2 \\
(1.2 \text { to } 8.7)\end{array}$ & $\begin{array}{l}6.2 \\
(1.8 \text { to } 21.2)\end{array}$ \\
\hline \multicolumn{4}{|c|}{$\begin{array}{l}\text { In Model } 1 \text { risk estimates were adjusted for age, sex and practice. } \\
\text { In Model } 2 \text { risk estimates were adjusted for age, sex, practice, and } \\
\text { characteristics of pain at baseline (frequency and associated disability). } \\
\text { In Model } 3 \text { risk estimates were adjusted for age, sex, practice, characteristics } \\
\text { of pain at baseline (frequency and associated disability), and combined } \\
\text { mental health score. }\end{array}$} \\
\hline
\end{tabular}

beliefs, ${ }^{30}$ pessimism over prognosis, ${ }^{31}{ }^{32}$ depression, ${ }^{28}$ and somatising tendency, ${ }^{28}$ while incident LBP pain has been linked with poor $\mathrm{SRH}^{33}$ and poor SF-36 $\mathrm{MH}^{34}$ our data imply that similar basic relationships hold for incidence and persistence of pain at the knee.

Direct support for this inference from other sources is limited. In contrast to LBP, there have been few studies of incident knee pain in the community, ${ }^{16}{ }^{35}$ and none of the persistence of knee pain as such, although there have been a few investigations of persistent pain in established cases of OA from the community. ${ }^{13} 16^{17}$ Few knee pain studies have explored mental health and belief variables as potential risk factors. Indeed, we believe this to be the first community-based cohort study of mental health factors, self-rated health, beliefs and incident knee pain. The findings on somatising tendency as a predictor of incidence and persistence also appear to be novel. However, two studies have reported that self-efficacy beliefs (negative self-beliefs about performance capability) are longitudinal predictors of decline in function, ${ }^{17}{ }^{35}$ and one follow-up study of established knee OA suggested that poor SF-36 MH predicts a poor functional outcome at 18 months. ${ }^{17}$ A recent study among knee pain consulters from Dutch primary care found also that somatic distress (assessed by the short version of the Four Dimension Symptom Questionnaire) was a significant predictor of less favourable changes in pain intensity at 3 and 12 months, and less favourable function at 12 months. $^{6}$

Our findings also agree with several cross-sectional studies involving community samples. Thus, in a postal survey of 4057 adults from Nottingham, the odds of knee pain were doubled, and those of disabling knee pain raised 4.7-fold in subjects with poor SF-36 MH; ${ }^{3}$ in a cohort of newly employed workers, the odds of knee pain in the past month were doubled in those with psychological distress (General Health Questionnaire score $\geqslant 3$ vs. 0$) ;{ }^{36}$ in the cross-sectional phase of the current study, we reported strong associations between somatising tendency and disabling or chronic knee pain, ${ }^{18}$ and among 374 subjects from a study of ageing in Baltimore, anxiety scores were associated with a lifetime history of knee pain, with differences confined to those with normal radiological findings. ${ }^{10}$ However, crosssectional studies reveal little about cause and effect. Thus, Hannan et al found it "unclear whether anxiety is a risk factor 
for pain reporting, or whether ... subjects were more anxious because they had pain" ${ }^{\prime \prime}{ }^{10}$ and similarly, at baseline, we raised a question as to whether subjects with a low threshold for being bothered by somatic symptoms more readily reported distressing regional pain, or whether the experience of chronic pain heightened bodily awareness of physiological events. ${ }^{18}$ In studies of persistence, even a prospective design may not circumvent the pitfall of reverse causation, as more severe symptoms at baseline may cause psychological distress and at the same time carry a worse prognosis. The most persuasive evidence on causal relations comes from cohort studies of incidence.

Our report adds to the sum of knowledge in providing incidence data and in confirming that mental health and health beliefs are factors in incident knee complaints as well as in the persistence of old knee complaints. Associations were particularly strong for knee pain that was medically treated-an effect that could reflect perceptions about severity, or illness behaviour, or both. Whichever the case, our findings support the hypothesis that knee pain in the community shares several risk factors in common with other non-specific regional pain syndromes.

\section{ACKNOWLEDGEMENTS}

We are grateful to the five general practices from Avon that allowed us to approach their patients and assisted with the initial sampling; also to Gwen Coombs and the MRC staff in Southampton and Bristol who helped with co-ordinating the follow-up mailing; the staff who assisted with data processing and programming support; and the patients who participated in the study. Denise Gould prepared the manuscript.

\section{Authors' affiliations}

K T Palmer, I Reading, C Linaker, D Coggon, MRC Epidemiology Resource Centre, Community Clinical Sciences, University of Southampton, Southampton General Hospital, Southampton, England SO16 6YD, UK M Calnan, MRC Health Services Research Collaboration, Department of Social Medicine, Canynge Hall, Bristol, England BS8 2PR, UK

Funding: This project was supported by the MRC Health Services Research Collaboration, Department of Social Medicine, University of Bristol and by core funding from the Medical Research Council.

Competing interests: None

\section{REFERENCES}

1 Peat G, McCarney R, Croft P. Knee pain and osteoarthritis in older adults: a review of community burden and current use of primary health care. Ann Rheum Dis 2001;60:91-7.

2 Jinks C, Jordan K, Ong BN, Croft P. A brief screening tool for knee pain in primary care (KNEST). 2. Results from a survey in the general population aged 50 and over. Rheumatology 2004;43:55-61.

3 O'Reilly SC, Muir KR, Doherty M. Knee pain and disability in the Nottingham community: association with poor health status and psychological distress. Br J Rheumatol 1998;37:870-3.

4 Dawson J, Linsell L, Zondervan K, Rose P, Carr A, Randall T, Fitzpatrick R. Impact of persistent hip or knee pain on overall health status in elderly people: a longitudinal population study. Arthritis Rheum 2005;53:368-74.

5 Jordan K, Jinks C, Croft P. A prospective study of the consulting behaviour of older people with knee pain. Br Gen Pract 2006;56:269-76.

6 van der Waal JM, Bot SD, Terwee CB, van der Windt DA, Scholten RJ, Bouter LM, Dekker J. Course and prognosis of knee complaints in general practice. Arthritis Rheum 2005;53:920-30.

7 Hadler NM. Knee pain is the malady-not osteoarthritis. Ann Intern Med 1992;116:598-599.

8 Creamer $\mathbf{P}$, Hochberg MC. Why does osteoarthritis of the knee hurt-sometimes? Br J Rheumatol 1997;37:726-8.

9 Peters TJ, Sanders C, Dieppe P, Donovan J. Factors associated with change in pain and disability over time: a community-based prospective observational study of hip and knee osteoarthritis. Br J Gen Pract 2005;55:205-11.
10 Hannan MT, Felson DT, Pincus T. Analysis of discordance between radiographic change and knee pain in osteoarthritis of the knee. J Rheumatol 2000;27:1513-17.

11 Davis MA, Ettinger WH, Neuhaus JM, Barclay JD, Segal MR. Correlates of knee pain among US adults with and without radiographic knee osteoarthritis. J Rheumatol 1992;19:1943-9.

12 Creamer P, Lethbridge-Cejku M, Costa P, Tobin JD, Herbst JH, Hochberg MC. The relationship of anxiety and depression with self-reported knee pain in the community: data from the Baltimore Longitudinal Study of Aging. Arthritis Care Res 1999; 12:3-7.

13 Brandt KD, Heilman DK, Slemenda C, Katz BP, Mazzuca S, Braunstein EM, Byrd D. A comparison of lower extremity muscle strength, obesity, and depression scores in elderly subjects with knee pain with and without radiographic evidence of knee osteoarthritis. J Rheumatol 2000;27:1937-46.

14 Jensen R, Hystad T, Baerheim A. Knee function and pain related to psychological variables in patients with long-term patellofemoral pain syndrome. $J$ Orthop Sports Phys Ther 2005;35:594-600.

15 McAlindon TE. The knee. Balliére's Best Pract Res Clin Rheumatol $1999 ; 13: 329-44$.

16 Peat G, Thomas E, Hand J, Wood L, Dziedzic K, Myers H, Wilkie R, Duncan R, Hay E, Hill J, Croft P. The Knee Clinical Assessment Study-CAS(K). A prospective study of knee pain and knee osteoarthritis in the general population. BMC Musculoskelet Disord 2004:5:4.

17 Sharma L, Cahue S, Song J, Hayes K, Pai YC, Dunlop D. Physical functioning over three years in knee osteoarthritis: role of psychosocial, local mechanical, and neuromuscular factors. Arthritis Rheum 2003:48:3359-70.

18 Palmer KT, Calnan M, Wainwright D, Poole J, O'Neill C, Winterbottom A, et al. Disabling musculoskeletal pain and its relation to somatization: A communitybased postal survey. Occup Med 2005;55:612-17

19 Palmer KT, Reading I, Linaker C, Calnan M, Coggon D. Population based cohort study of incident and persistent arm pain: role of mental health, self-rated health and health beliefs. In press.

20 Ware JE. SF-36 Health Status Questionnaire. Boston, MA: Institute for the Improvement of Medical Care and Health, New England Medical Center Hospital, Quality Quest Inc, 1989.

21 Derogatis LR, Melisaratos N. The Brief Symptom Inventory: an introductory report. Psychol Med 1983;13:595-605.

22 Eriksson I, Unden A-L, Elofsson S. Self-rated health. Comparisons between three different measures. Results from a population study. Int $J$ Epidemiol 2001;30:326-33.

23 McHorney CA, Ware JE Jnr, Lu JF, Sherbourne CD. The MOS 36 item ShortForm Health Survey (SF-36). III. Tests of data quality, scaling assumptions, and reliability across diverse patient groups. Med Care 1994;32:40-66.

24 Preston NJ, Harrison TJ. The Brief Symptom Inventory and the Positive and Negative Syndrome Scale: discriminate validity between a self-reported and observational measure of psychopathology. Compr Psychiatry 2003;44:220-6.

25 Miilunpalo S, Vuori I, Oja P, Pasanen M, Urponen H. Self-rated health status as a health measure: the predictive value of self-reported health status on the use of physician services and on mortality in the working-age population. J Clin Epidemiol 1997; 50:517-28.

26 Kannus $\mathbf{P}$, Jarvinen $M$, Kontiala $H$, Bergius L, Hyssy $E$, Salminen E, Tuomi $A$ Unkila T, Valtanen I. Occurrence of symptomatic knee osteoarthrosis in rural Finland: a prospective follow up study. Ann Rheum Dis 1987;46:804-8.

27 Felson DT, Zhang Y, Hannan MT, Naimark A, Weissman BN, Aliabadi P, Levy D. The incidence and natural history of knee osteoarthritis in the elderly. The Framingham Osteoarthritis Study. Arthritis Rheum 1995;38:1500-5.

28 Dionne CE, Koepsell TD, Von Korff M, Deyo RA, Barlow WE, Checkoway H. Predicting long-term functional limitations among back pain patients in primary care settings. J Clin Epidemiol 1997;50:31-43.

29 Thomas E, Silman AJ, Croft PR, Papageorgiou AC, Jayson MI, Macfarlane GJ. Predicting who develops chronic low back pain in primary care: a prospective study. BMJ 1999;318:1662-7.

30 Van der Weide WE, Verbeek JH, Salle HJ, van Dijk FJ. Prognostic factors for chronic disability from acute low-back pain in occupational health care. Scand J Work Environ Health 1999:25:50-6.

31 Karjalainen K, Malmivaara A, Mutanen P, Pohjolainen T, Roine R, Hurri H. Outcome determinants of subacute low back pain. Spine 2003;28:2634-40.

32 Gross BP, Battie MC. Work-related recovery expectations and the prognosis of chronic low back pain within a workers' compensation setting. J Occup Environ Med 2005;47:428-33.

33 Kopec JA, Sayre EC, Esdaile JM. Predictors of back pain in a general population cohort. Spine. 2004;29: 70-7; discussion 77-81.

34 Smith BH, Elliott AM, Hannaford PC, Chambers WA, Smith WC. Factors related to the onset and persistence of chronic back pain in the community: results from a general population follow-up study. Spine 2004;29:1032-40.

35 Rejeski WJ, Miller ME, Foy C, Messier S, Rapp S. Self-efficacy and the progression of functional limitations and self-reported disability in older adults with knee pain. J Gerontol B Psychol Sci Soc Sci 2001;56:S261-5.

36 Nahit ES, Pritchard CM, Cherry NM, Silman AJ, Macfarlane GJ. The influence of work related psychosocial factors and psychological distress on regional musculoskeletal pain: a study of newly employed workers. J Rheumatol 2001 ;28: 1378-84. 